\title{
Erythrocyte Sedimentation Rate Values in Pulmonary Tuberculosis Vs Normal Healthy Peoples in Khammam region of Telangana, India
}

Mahalakshmamma. V ${ }^{1}$, Eliya Raju. A*2, Jhansi. $K^{3}$.

${ }^{1}$ Associate .Prof, Department of Physiology, Mamata Medical College, Khammam, Telangana, India.

*2,3 Tutor, Department of Physiology, M amata M edical College, Khammam, Telangana, India.

\section{ABSTRACT}

Erythrocyte Sedimentation Rate (ESR) is a marker for inflammation in the body. It is the initial test carried out in order to detect infection using Westergrens tube in which ante cubital venous blood is mixed with sodium citrate as an anticoagulant. A study was performed in, pulmonary tuberculosis patients who were taking treatment in hospital and normal young healthy individuals were randomly selected as controls. They were divided into 3 Groups, Group-1 normal and pulmonary tuberculosis patients, Group-2 before treatment and after treatment, Group-3 contains BM I for Both Groups, mean SD and $p$ values are statistically studied by using ANOVA. ESR may help to find out the progrnosis of the disease. Determination of ESR after the treatment with anti tubercular drugs helps in determine the effectiveness of the drugs used and there by estimate the prognosis of the disease.

KEY WORDS: (ESR) Erythrocyte Sedimentation Rate, Westergreens Method, Pulmonary Tuberculosis, Healthy People, Prognosis.

Address for correspondence: M r. Eliya Raju. A, (Tutor), Department of physiology, M amata M edical College, Khammam, Telangana, India. Ph 09849512797/09059369200

E-Mail: annepakaeliyaraju@gmail.com,cool.eliyaraj@gmail.com

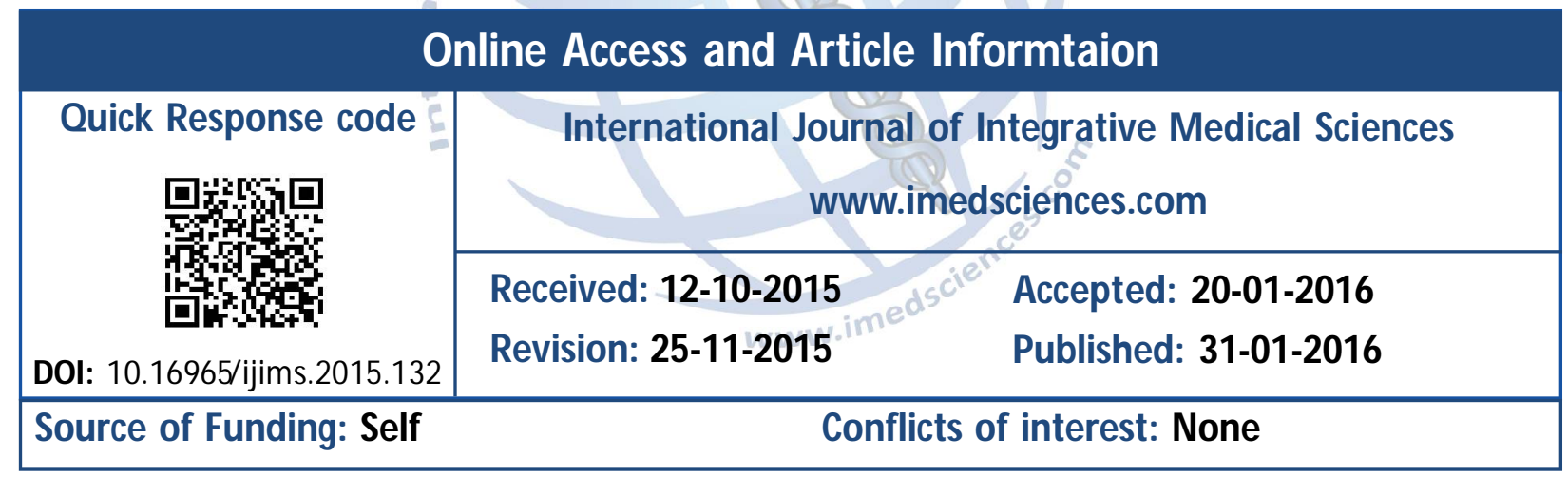

\section{INTRODUCTION}

Erythrocyte sedimentation rate is one of the oldest and most frequently utilized laboratory methods. It is a non Specific test, it has been found useful in monitoring response to clinical therapy, especially in tuberculosis. RBCs remain suspended uniformly in circulation; this is called suspension stability of RBCs. If blood is mixed with an anticoagulant and allowed to stand on a vertical tube, the red cells settle down due to gravity with a supernatant layer of clear plasma. This test was invented in 1897 by the Polish doctor Edmund Biernacki . In some parts of the world the test continues to be referred to as the Biernacki Test (Polish abbreviation: $O B=$ OdczynBiernackiego). In 1918, the Swedish pathologist Robert SannoFåhræus declared the same and along with Alf Vilhelm Albertsson Westergren are eponymously remembered for the Fåhræus-Westergren test (abbreviated as FW test; in the UK, usually termed Westergren's test) which used sodium citrate-coagulated specimens. Westergren's normal values, for men $3 \mathrm{~mm}$ and women $7 \mathrm{~mm} /$ first one hour [1]. Tuberculosis (TB), It is a highly prevalent chronic infectious disease caused by bacterium (bacillus) Mycobacterium tuberculli characteristically it prefers respiratory tissues which are always in contact with high oxygen levels, as in the lung tuberculosis disease is transmitted from an infected person to another person through air 
born means such as coughing, sneezing, spitting and even speaking [2]. The comprehensive investigations on hematological changes and abnormalities associated to tuberculosis is still lacking.

\section{MATERIALS AND METHODS}

Study was carried out with 30 pulmonary tuberculosis patients who were taking treatment in Mamata General hospital at Khammam district (TS) in India and 30 normal healthy individuals form the same place, who are willing to participate, for the study included the both genders within the age group of 13 to 75 years and they were selected randomly. Inclusive Criteria for the study is that Pulmonary tuberculosis patients, diagnosed of pulmonary tuberculosis based on clinical and biological evidence of smear positive for acid fast bacilli by Ziehl -Neelsen Staining [2]. Freshly diagnosed and treated patients, Including the smokers, alcoholics \& diabetic patients. Exclusion Criteria in the patients of pulmonary tuberculosis with associated conditions like, HIV infections, severe pulmonary lung disorders and patients those who are taking 3 basic drugs of treatment namely: Streptomycin, (antimycobacterial drug) Rifamycin, it is a antibiotic used to treat a number of bacterial infections Isoniazid, (marketed under other names including isonicotinylhydrazide (INH) and Hydra,) it is a antibiotic used as a first-line of agent in the prevention and treatment of both latent and active tuberculosis. These 3 drugs were given to the patients and hospitalized for 3 weeks or more for the treatment.

Procedure: Blood sample collection was under aseptic conditions $2 \mathrm{ml}$ of blood is drawn from ante cubital vein and transferred into a penicillin bottle containing $0.5 \mathrm{ml}$ of $3.8 \%$ sodium citrate solution (anticoagulant) and mix with anticoagulant The erythrocyte sedimentation rate was estimated by Westergrens method [3]
Carefully suck the citrated blood into the Westergrens pipette up to the level of zero mark and immediately close pipette upper opening with the thumb to prevents blood from running down. Then press the lower pipette end tightly place on a rubber pad to prevent blood from escaping out, then fix it an exactly vertical position in the westegrens strand. Then Record the time wait for one hour take the reading of ESR.

Height and Weight: Were measured by using weighing machine and expressed in $\mathrm{cm}$ and $\mathrm{kg}$ respectively. Body Mass Index derived from Quetelet's index.

\section{RESULTS}

Statistical Analysis: Results obtained were complied and statistical significance was found out by ANOVA, Applying paired t test and bar diagrams constructed as per the data compiled.

Graph 1: Showing increased levels of Mean, SD values for the ESR in tuberculosis patients as compared to normal individuals.

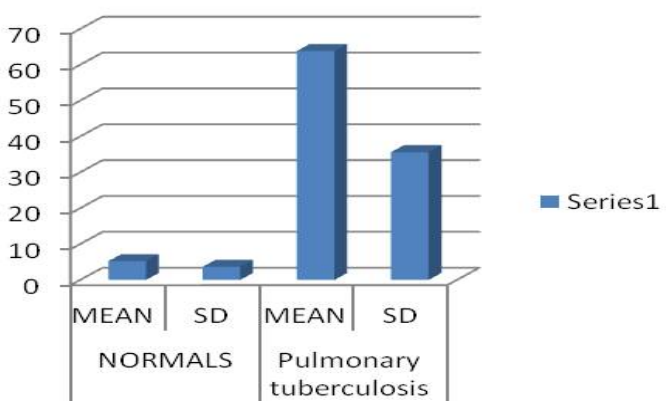

Graph 2: Showing the Mean, SD values of ESR in pulmonary tuberculosis during the pre and post treatment sessions with anti tubercular drugs.

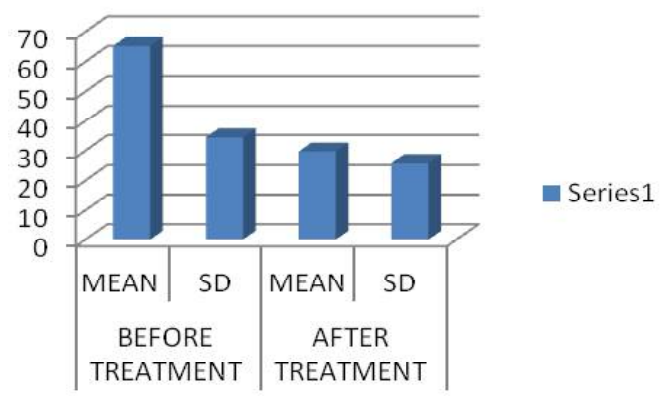

Table 1: Showing the M ean, SD and $P$ values of among the three groups.

\begin{tabular}{|c|c|c|c|c|c|c|}
\hline & \multicolumn{2}{|c|}{ Group-1 } & \multicolumn{2}{c|}{ Group-2 } & \multicolumn{2}{c|}{ Group-3 } \\
\hline & NORMAL & $\begin{array}{c}\text { PULMONARY } \\
\text { TUBERCULOSIS }\end{array}$ & $\begin{array}{c}\text { BEFORE } \\
\text { TREATM ENT }\end{array}$ & $\begin{array}{c}\text { AFTER } \\
\text { TREATMENT }\end{array}$ & NORMAL BMI & $\begin{array}{c}\text { PULMONARY } \\
\text { TUBERCULOSIS } \\
\text { BMI }\end{array}$ \\
\hline MEAN & 5.233 & 63.83 & 65.3 & 29.73 & 21.31 & 17.72 \\
\hline SD & 3.645 & 35.62 & 34.47 & 25.8 & 3.295 & 3.575 \\
\hline p value & \multicolumn{3}{|c|}{$\varangle 0.05$} & \multicolumn{2}{|c|}{0} & \multicolumn{2}{c|}{$\varangle .05$} \\
\hline
\end{tabular}


Graph 3: Mean, SD values of BMI variation in normal healthy individuals \& patients with pulmonary tuberculosis.

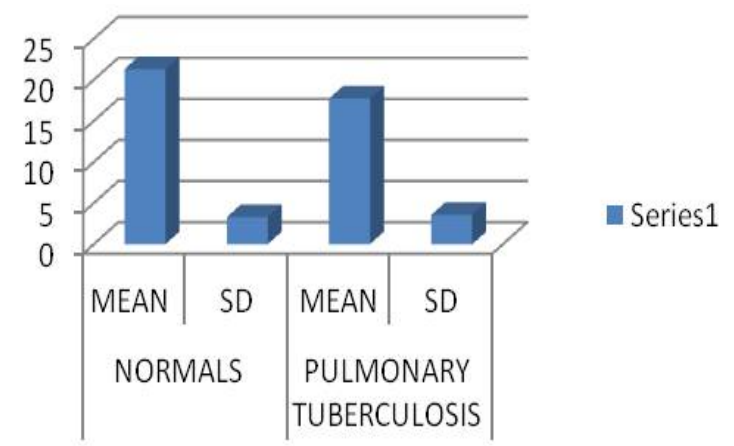

\section{DISCUSSION}

For the estimation of ESR, the blood is mixed with an anticoagulant and allowed to stand on a vertical tube the red cells settle down due to the gravity with a supernatant layer of clear plasma. ESR also called Erythrocyte sedimentation rate. Inflammation in the body often causes the release of proteins into the blood, which can make red blood cells are more sticky. The sticky cells are more likely to clump together, increasing the rate with which they sink to the bottom of the tube and causing a corresponding rise in erythrocyte sedimentation rate levels. The present study shows that there is increased level of ESR in tuberculosis patients as compared to normal individuals, it is significant ( $p \varangle 0.05$ ) in the Graph-1 and Fatima Tashpulatova studied (2011) [4] reported that there was a high ESR level in patients having advanced active tuberculosis, but irrelevant increase in ESR was common, limiting its usefulness. Al-M arri MR, Kirkpatrick MB.et al (2000) [5] also showed that there is significant increased levels of Erythrocyte sedimentation rate in childhood tuberculosis my study approves his work. The Body mass index of the Tuberculosis patients is also found to be significantly lower than healthy control ( $p$ $\varangle 0.05)$ (Graph-3), which correlates well with the I S Ukpe, L Southern et al [6] study, on malnutrition is observed frequently in patients with pulmonary tuberculosis (TB), underweight patients are highly affected due to imbalance diet ingested as compared to normal's. On the contrary the reduction in body mass index may be due to pulmonary tuberculosis. If it is chachexia and responsible for anorexia. The values of erythrocyte sedimentation rate in pulmonary tuberculosis (Graph-2) are significantly decreased after treatment with anti tubercular drugs, $(p=0.00)$ and indicate good response to treatment and a good prognosis. When the results of the study conducted by DINESH KOJU et al (2005)[7] compared to those of the present study, that the treatment with anti tubercular drugs, the ESR values which were higher at before treatment, the reduction after treatment, at the beginning of the tuberculosis process there is strong pro-inflammatory cytokine activity (IFN $-\gamma \&$ TNF - $\alpha$ ) which stimulates the expression of acute phase proteins, as the disease involutes, the inflammation process cools down. V. M. Oliva et al [8] ESR can be as a marker of severity of the disease, before treatment with anti tubercular drugs and effectiveness of the drugs said drugs and good or bad prognosis after treatment. The authors of the article, Causes of high erythrocyte sedimentation rates in an inpatient population, commented that traditionally it has been taught, without substantiating evidence [7], that very high erythrocyte sedimentation rate (ESR) values $(\geq 100 \mathrm{~mm} /$ h) are associated with tuberculosis (TB).

\section{CONCLUSION}

From the above observations it can be concluded that the ESR significantly increases in pulmonary tuberculosis and with adequate treatment with anti tubercular agents (drugs), the ESR significantly decrease also. Tuberculosis is a destructive disease as well as a chronic disease and therefore, fibrinogen and gamma globulin levels increase .which will increase rouleaux formation and thereby ESR Greater the level higher is the ESR and which may help to find out the gravity of the disease process. Determination of ESR after the treatment with anti tubercular drugs help determine the effectiveness of the drugs used and thereby the prognosis if good or bad. Anti tubercular drugs (streptomycin, isoniazid, refampacin) that have been used are the drugs that effectively decrease and effectiveness of anti tubercular therapy and a good or a bad prognosis.

\section{REFERENCES}

[1]. Shruti Kumta, Gireesh Nayak, et al. A COM PARATIVE STUDY OF ERYTHROCYTE SEDIM ENTATION RATE (ESR) USING SODIUM CITRATE AND EDTA International Journal of Pharmacy and Biological Sciences 2011;1(4):393-396. 
[2]. Imam, T. S, Oyeyi, T.I. et al. A RETROSPECTIVE STUDY OF PULM ONARY TUBERCULOSIS (PTB)PREVALENCE AMONGST PATIENTS ATTENDING INFECTIOUS DISEASESHOSPITAL (IDH) IN KANO, NIGERIA Bajopas 2008;1(1).

[3]. Bharathi Vennapusa, MD, et al. Erythrocyte Sedimentation Rate (ESR) M easured by the Streck ESR-Auto Plus Is Higher Than With the Sediplast Westergren M ethod. American Journal of Clinical Pathology, 2011;135:386-390. doi:10.1309/ AJCP48YXBDGTGXEV

[4]. Fatima Tashpulatova et al. Forecasting the risk of medicinal complications from the chemical therapy inpatients with multi-resistant pulmonary tuberculosis European Respiratory Society. 38:55.

[5]. Al-M arri MR, Kirkpatrick MB et al. Erythrocyte sedimentation rate in childhood tuberculosis: is it still worthwhile? Int J Tuberc Lung Dis. 2000 Mar;4(3):237-9.
[6]. ISUkpe, L Southern et al Erythrocyte sedimentation rate values in active tuberculosis with and without HIV co-infection Article In South African Medical Journal =Suid-Afrikaanse Tydskrif Vir Geneeskunde. June 2006. https://www.researchgate.net/ publication/7030899 ' Source: Pub M ed

[7]. Dinesh Koju, B.SRao et al. Occurrence Of Side Effects From Anti-Tuberculosis Drugs In Urban Nepalese Population Under Dots Treatment Kathmandu University Journal Of Science, Engineering And Technology 2005;I(1).

[8]. V. M. Oliva et al. Pulmonary Tuberculosis: Hematology, Serum Biochemistry And The Relation With The Disease Duration. J. Venom. Anim. Toxins incl. Trop. Dis., 2008;14(1):72.

\section{How to cite this article:}

M ahalakshmamma. V, Eliya Raju. A, Jhansi. K. Erythrocyte Sedimentation Rate Values in Pulmonary Tuberculosis Vs Normal Healthy Peoples in Khammam region of Telangana, India. Int J Intg M ed Sci 2016;3(1):207-210. DOI: 10.16965 / ijims.2015.132 